Van Roy, J.; Leemput, N.; Geth, F.; Salenbien, R.; Büscher, J.; Driesen, J., "Apartment Building Electricity System Impact of Operational Electric Vehicle Charging Strategies," in IEEE Transactions Sustainable Energy, vol. 5, no. 1, pp. 264-272

doi: 10.1109/TSTE.2013.2281463

URL: http://ieeexplore.ieee.org/stamp/stamp.jsp?tp=\&arnumber=6650062\&isnumber=5433168

(C2013 IEEE. Personal use of this material is permitted. Permission from IEEE must be obtained for all other uses, in any current or future media, including reprinting/republishing this material for advertising or promotional purposes, creating new collective works, for resale or redistribution to servers or lists, or reuse of any copyrighted component of this work in other works. 


\title{
Apartment Building Electricity System Impact of Operational Electric Vehicle Charging Strategies
}

\author{
Juan Van Roy, Student Member, IEEE, Niels Leemput, Student Member, IEEE, Frederik Geth, Student \\ Member, IEEE, Robbe Salenbien, Jeroen Büscher, Member, IEEE, and Johan Driesen, Senior Member, IEEE
}

\begin{abstract}
This paper discusses the charging of multiple plugin hybrid electric vehicles in an apartment building, equipped with a photovoltaic system. Different charging strategies and charging power ratings are examined, which are assessed in terms of their grid impact, the self-consumption of local electricity generation and the electric driving range. The impact of a residential building, which incorporates EV charging, on the distribution grid can be significantly reduced by using simple EV charging strategies. These strategies include complementing nighttime with daytime charging, peak shaving at vehicle level and charging the surplus of local generation. Effective results are obtained using only knowledge of the present battery state of charge, next departure time and the instantaneous local generation surplus. The simultaneity of the EV charging and the photovoltaic production increases. The increase in electric driving range is negligible for three-phase charging.
\end{abstract}

Index Terms-Distributed coordinated charging, Electric vehicles, Photovoltaic system, Residential building charging.

\section{INTRODUCTION}

G LOBALLY, approximately $32 \%$ of the total energy use is consumed in residential and commercial buildings [1]. Residential and commercial buildings are responsible for about $30 \%$ of the global total end-use energy-related $\mathrm{CO}_{2}$ emissions, if the indirect upstream emissions are considered [1].

European climate and energy goals for 2020, i.e. the 20/20/20 targets, are set by the European Commission [2]. One of the targets is a $20 \%$ improvement in the EU's energy efficiency compared to a business-as-usual scenario. Energy goals and benchmarks at the level of individual buildings are stated in the European Directive 2002/91/EC, which is recasted in Directive 2010/31/EU [3]. It is stated that by 2020 all new buildings need to be nearly zero energy buildings (nZEB), targeting a high penetration of renewable energy resources (RES) and a high energy efficiency in the built environment, although the definition of an nZEB is not clearly defined.

Multiple definitions for ZEBs are available in the literature [4]. A ZEB requires increases of both the integration of local RES and energy efficiency (e.g. proper insulation). The latter also includes a further electrification through new, more efficient technologies such as electric vehicles (EVs) and

J. Van Roy is funded through a VITO doctoral scholarship. N. Leemput is a doctoral research assistant of IWT-Vlaanderen.

All authors are with EnergyVille, 3600 Genk, Belgium

J. Van Roy, N. Leemput, F. Geth, J. Büscher and J. Driesen are with the University of Leuven (KU Leuven), Department of Electrical Engineering (ESAT), Division ELECTA, Kasteelpark Arenberg 10, PB 2445, 3001 Leuven, Belgium (e-mail: Juan.VanRoy@esat.kuleuven.be).

J. Van Roy and R. Salenbien are with the Flemish Institute for Technological Research (VITO), Unit Energy Technology, 2400 Mol, Belgium. heat pumps (HPs). These have a certain flexibility to shift the power consumption in time [5], [6] and significantly reduce the consumption of greenhouse gas emitting fuels and local pollutant emissions [1], [7].

However, from the grid point of view, these new technologies have a twofold impact. First, the power consumption will increase. Second, there is an increased grid impact. To minimize the latter, a proper synchronization of consumption and production of both electricity and heat is needed through demand side management (DSM), electrical and thermal storage and minimizing the power consumption [1].

\section{A. Impact on the Power Consumption}

EVs will increase the power consumption in buildings. For full electric vehicles, charging the vehicle at home only will nearly double the average household power consumption $(3,500 \mathrm{kWh}$ per year in Flanders [8]). Given the Flemish mobility behavior, the specific power consumption of existing vehicles and a typical charging efficiency of $90 \%$, this results in an additional power consumption of about 2,350 to $3,750 \mathrm{kWh}$ per household using an EV [9].

Charging at home might be complemented with charging at other locations (e.g. work and parking spots), which decreases the impact on the household power consumption.

\section{B. Impact on the Electricity Grid}

The intermittent production character of RES and its potential non-simultaneity with the power consumption has a grid impact on the level of both the distribution (DSO) and transmission system operator (TSO).

Photovoltaic (PV) systems and EVs have an increasing impact on the low-voltage (LV) distribution grid [10]. The injection of electricity by means of PV systems and the power consumption of EVs may lead to peak loads and higher resistive losses. As LV grids are mainly resistive, voltage deviations and phase unbalance occur due to the active power flows [10]-[13]. For instance, nighttime charging is often preferred for load-leveling purposes on the transmission grid level. However, for a high local EV penetration rate, new peak loads may arise in the distribution grid due to a high simultaneity with the evening household power consumption.

Therefore, it is important to analyze coordination strategies, which reduce the impact of EV charging on the grid, in order to minimize the impact of these technologies on the lifetime of e.g. the distribution grid assets. Peak shaving can e.g. be implemented to smoothen out the power profile and to increase the simultaneity with local generation [11]. 


\section{Flexibility of EVs for Charging Coordination}

Passenger vehicles stand still over $90 \%$ of the time. This offers charging flexibility, e.g. by spreading the charging by charging at a lower power, while respecting the mobility requirements. Fig. 1 shows the average availability of a Flemish vehicle fleet at home, at work and at other locations [9].

Fig. 1 also shows a normalized household synthetic load profile for a random day [8]. The evening peak coincides with the arrival of the EVs at home during the evening. As mentioned in Section I-B, the EV charging may increase the household load peak. During daytime, on average more than $20 \%$ of the vehicles are parked at home. This allows for additional daytime charging, which can decrease the impact of evening and nighttime residential EV charging and increase the simultaneity with local PV production.

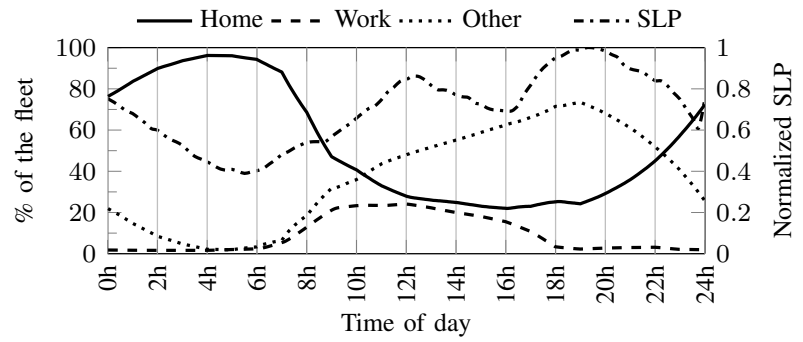

Fig. 1. Average availability during a day of a Flemish vehicle fleet at home, at work and at other locations (including being on the road) [9] and a random normalized residential synthetic load profile (dashdotted line) [8]

The charging flexibility of EVs is limited by the mobility objective, the available charging power ratings, battery state of charge (SOC) and battery limitations. This flexibility can be represented by a flexibility curve (see Fig. 2). This graph defines a solution set of possible charging paths, limited by an upper and lower bound curve which give respectively the operation curve without any delay and with maximum charging delay. For instance, the trend towards higher charging powers increases the charging flexibility. Also, this flexibility represents an opportunity to coordinate the EV charging [14].

This approach is also valid for other technologies, such as heat pumps and combined heat and power units, which provide a certain flexibility to shift the generation of heat and the consumption and production of electricity [6], [15]. In future work, these technologies should be combined with the EV charging integration in buildings. This may result in improved solutions for the integration of these technologies in buildings.

The opportunities for vehicle-to-building (V2B) and vehicle-to-grid (V2G) services are envisioned [13], as well as mechanisms such as droop-based voltage support [16].

\section{Coordinated Charging}

The coordination of EV charging has been investigated on several scales in the literature. Besides, the integration with renewables has been studied [14]. The focus of EV charging on the building scale mainly focusses on the optimization for technical and/or economical objectives. As a technical objective, e.g. a peak shaving objective is implemented which uses

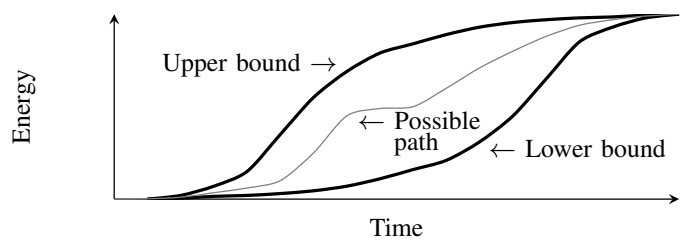

Fig. 2. A flexibility curve, indicating the possible charging paths and upper (no charging delay) and lower limits (maximum charging delay).

the information from the building and/or district level to coordinate the EV charging [17]-[20]. Other studies coordinate the EV charging in buildings by cost minimization [21]-[23]. Similar approaches can be found for EV charging coordination on the distribution grid level [11], [14].

These coordination strategies mainly require the knowledge during a certain optimization horizon of e.g. the EV behavior, the power consumption of the buildings or grid and electricity cost. Also extensive communication infrastructure may be required. Other coordination strategies, which require minimal prior knowledge and communication, such as grid stabilizing strategies [16], are not widely discussed in the literature.

However, for the initial EV rollout and before a widespread coordination is expected, the cost of charging infrastructure should be low [24] and should be weighed against the benefits and drawbacks [25]. Also, high EV penetrations may first occur on the local level exceeding local technical grid limits.

Therefore, simple operational charging strategies, which do not require an EV charging optimization and which can be easily implemented, e.g. on the on-board battery management system, are discussed in this paper. The investigated strategies only require the knowledge of the next departure time, a measurement of the present battery state of charge and local generation and which require minimal communication infrastructure.

\section{E. Scope of Paper}

This paper focuses on the impact of different EV charging strategies in large residential buildings. The strategies are compared in terms of their distribution grid impact, the selfconsumption of local generation and the EV utility factor.

The investigated charging strategies include only charging during the night and a combination in which daytime charging complements nighttime charging. Charging can start arriving at home at full charging power or can be postponed as long as possible, which allows to investigate the impact of the upper and lower limits of the EV charging flexibility (see Fig. 2).

Individual peak shaving at vehicle level allows to use the full flexibility of the EV by charging at a lower charging power in order to fully charge the EV by the next departure time without influencing the mobility requirements. Besides, different charging power ratings are investigated for their benefits and disadvantages regarding the trend towards higher charging power ratings for residential EV charging.

These strategies allow to discuss what is feasible with simple implementable strategies before implementing widespread coordination mechanisms to meet the stakeholders' technical objectives, and the benefits for the different actors. 


\section{Methodology}

The assessment is performed in Modelica, an open source, object-oriented and equation based modeling language. The electrical models are part of the KU Leuven IDEAS tool [12].

\section{A. Grid Impact}

It is important to take into account the grid impact of different technologies and coordination strategies for EV charging. An overview of several grid impact indicators is available in the literature [26], [27].

The bidirectional power flow exchanges between the building and the distribution grid will be assessed for the different EV charging strategies, EV charging power ratings and EV penetration levels. Modified box plots are used to represent the load duration diagrams. Besides, the one percent peak power (OPP) is calculated for each scenario. The OPP is defined as the mean power of the one percent highest power peaks [27]. In this paper, the OPP is calculated separately for both the demand and injection powers.

\section{B. Self-consumption}

Cover factors are defined to quantify the mismatch between local demand and production of a certain energy flow. They represent the ratio of the local supply to the local demand (self-consumption, $\gamma_{S}$ ) and vice versa (self-generation, $\gamma_{D}$ ).

The electric cover factors, defined in [27], are calculated as:

$$
\gamma_{x}=\frac{\int_{t_{1}}^{t_{2}} \min \left\{P_{S}, P_{D}\right\} d t}{\int_{t_{1}}^{t_{2}} P_{x} d t},
$$

with $x \in[S, D] \cdot \gamma_{S}$ and $\gamma_{D}$ are respectively the electric supply and demand cover factors. $P_{S}$ and $P_{D}$ are respectively the local electricity supply and demand. The ZEB level is reached when $\int P_{S} d t=\int P_{D} d t$, which is valid when $\gamma_{S}=\gamma_{D}$.

\section{Utility factor of EVs}

EPRI has defined a utility factor (UF) for individual PHEVs [7]. The UF is defined as the ratio of the annual electric kilometers and the annual vehicle kilometers traveled. This factor varies for each PHEV and depends on the charging opportunities, the distances traveled and the all-electric range of the EV.

\section{SCENARIO DESCRIPTION}

This section gives a description of the models and the scenarios. Two new models are created in Modelica, namely a battery storage and an EV model.

\section{A. Apartment Building}

An apartment building for the Brussels-Capital Region is chosen as a representative case for the residential power consumption and sizing of the PV installation [28]. The building consists of five floors with four individual apartments each and a ground floor with garage space. It is assumed that there is one garage per apartment. Each flat has a floor surface of
$89 \mathrm{~m}^{2}$. Therefore, it is assumed that the roof has a total area of $356 \mathrm{~m}^{2}$. Due to shading effects (e.g. tilted PV panels and other obstacles) the roof can only be partially covered with a perfect oriented PV installation. This available surface has been set to $65 \%$ of the roof surface, i.e. $231 \mathrm{~m}^{2}$ [29].

The average household power consumption of a typical family in Flanders is $3500 \mathrm{kWh}$ per year [8]. A synthetic load profile (SLP) is used to represent the total power consumption of the building. The SLP represents the average power profiles of the Flemish residential electricity consumers. Yearly SLPs are available with a 15-minute resolution [8]. This approach is only valid when aggregating multiple households, since one household typically has a power profile with faster varying temporal load profiles.

\section{B. Photovoltaic System}

The PV production profile is generated using the fiveparameter model of [30], which is temperature-dependent. The model is implemented in Modelica [31]. Meteorological data for Uccle in Belgium is used [32]. Based on the manufacturer data and the available roof area, the PV system has a peak power of about $38.9 \mathrm{~kW}$.

The calculations are based on characteristics that are provided by the solar panel manufacturer [33]. The required specifications are the current $I_{m p p}$ and voltage $V_{m p p}$ at maximum power point under standard testing conditions (STC), the short circuit current $I_{s c}$ and open circuit voltage $V_{o c}$ under the same STC and the temperature coefficients of respectively the short circuit current $k_{i}$ and open circuit voltage $k_{v}$. The parameter values are listed in Table I. The DC power output is converted to an active $\mathrm{AC}$ power by means of an inverter with a constant efficiency of $95 \%$. It is assumed that the panels are perfectly oriented southwards with an optimal inclination of $34^{\circ}$. This fixed orientation results in the maximum annual electricity production for the considered location. This perfect orientation is a valid assumption for flat roofs.

TABLE I

PV PANEL RATINGS AND PARAMETERS AS GIVEN BY A MANUFACTURER [33].

\begin{tabular}{rrrrll}
\hline$I_{m p p}$ & {$[\mathrm{~A}]$} & 6.71 & $V_{o c}$ & {$[\mathrm{~V}]$} & 42.3 \\
$V_{m p p}$ & {$[\mathrm{~V}]$} & 34.3 & $k_{i}$ & {$\left[m A /{ }^{\circ} \mathrm{C}\right]$} & 2.17 \\
$I_{s c}$ & {$[\mathrm{~A}]$} & 7.22 & $k_{v}$ & {$\left[\mathrm{~V} /{ }^{\circ} \mathrm{C}\right]$} & -0.106 \\
\hline
\end{tabular}

\section{Electric Vehicles}

The EV model consists of three submodels: that of a battery, the mobility behavior and the charging behavior.

1) Battery model: The implementation of the battery model is based on the model used in [34], which consists of the dynamic SOC equations and the battery parameter constraints. The SOC at each time step $t$ is calculated by:

$$
S O C_{t}=S O C_{t-1}-\delta_{t}^{s d}+\Delta S O C_{t-1}^{t},
$$

with $\delta_{t}^{s d}$ the self-discharge of the battery in a time step $t$ and $\Delta S O C_{t-1}^{t}$ the difference in SOC in the period $[t-1, t]$. To 
extend the battery cycle life [35], the usable battery capacity is limited to $80 \%$ of the total capacity.

Lithium-ion (Li-ion) batteries are chosen for the EVs. The charge $\eta_{c}$ and discharge efficiencies $\eta_{d}$ of the power electronics and battery and the self-discharge $\delta_{s d}$ are respectively $88.2 \%, 98.0 \%$ and $3.0 \%{ }_{S O C} /$ month.

The EVs are modeled as PHEVs such that all mobility requirements are met, even if the battery is depleted. The total battery capacities are 20,30 and $40 \mathrm{kWh}$ for respectively the subcompact, midsize and large vehicles (see Section III-C2).

2) Mobility Behavior: A mobility simulation tool is used to generate the mobility behavior profiles for a fleet of EVs [9]. To have a realistic driving pattern for each individual vehicle in the fleet, statistical data on Flemish transport behavior is used in this tool. It is assumed that the mobility behavior with EVs remains the same as with conventional vehicles. This tool creates a unique behavior for each vehicle: whether the vehicle is driving or standing still and where it is parked (e.g. at home, at work, or at a visit). Fig. 3 gives a one-day driving pattern example for one vehicle.

The variation of vehicle types and vehicle fuels (gasoline and diesel) on the yearly driven distance in the Flemish vehicle fleet is taken into account. Therefore, the vehicles are divided in subcompact, midsize and large vehicles. These vehicle categories have each their specific power consumption. To take into account the impact of parameters such as the ambient temperature, wind, altitude, road grade and surface, the specific power consumption calculated in [9] is increased with a correction factor of $15 \%$ [36]. The specific power consumption values are respectively $0.185,0.220$ and $0.293 \mathrm{kWh} / \mathrm{km}$.

3) Charging Strategies: Only the possibility to charge at home is considered. This can be considered as the worstcase from the building point of view. Two periods of charging are considered: charging during the day $(6 \mathrm{am}-10 \mathrm{pm})$ and night $(10 \mathrm{pm}-6 \mathrm{am})$. These periods coincide with the present double day-night tariff periods in Belgium.

The investigated charging strategies are depicted in Table II. At night, all EVs start charging when arriving at home, either at maximum charging power or with a reduced charging power (individual peak shaving). This reduced power for individual peak shaving is calculated from the next departure time and the required energy to fully charge the battery by the departure time. During daytime, one or more strategies are possible:

- Uncoordinated (D.1): Charging starts after arrival at home, either at maximum charging power or with a reduced charging power (individual peak shaving).

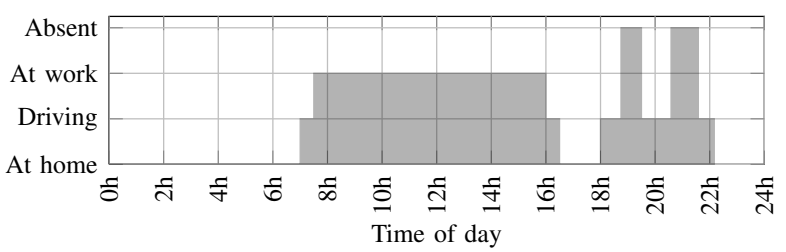

Fig. 3. A one-day driving pattern example for a vehicle. A vehicle can be driving and it can be parked at home, at work or another location (absent).
TABLE II

OVERVIEW OF EV CHARGING STRATEGIES DURING DAYTIME AND THE AVAILABILITY OF INDIVIDUAL PEAK SHAVING DURING THE DAY/NIGHT. STRATEGIES 1 AND 2 ONLY INCLUDE NIGHTTIME CHARGING.

\begin{tabular}{cccccc}
\hline $\begin{array}{c}\text { Charging } \\
\text { Strategy }\end{array}$ & \multicolumn{2}{c}{$\begin{array}{c}\text { Daytime (6h-22h) } \\
\text { strategy }\end{array}$} & \multicolumn{2}{c}{$\begin{array}{c}\text { Individual } \\
\text { peak shaving }\end{array}$} \\
\cline { 2 - 6 } & D.1 & D.2 & D.3 & Night & Day \\
\hline 1 & & & & & \\
2 & & & & $\mathrm{x}$ & \\
3 & $\mathrm{x}$ & & & & \\
4 & $\mathrm{x}$ & & & $\mathrm{x}$ & $\mathrm{x}$ \\
5 & & $\mathrm{x}$ & $\mathrm{x}$ & & \\
6 & & $\mathrm{x}$ & $\mathrm{x}$ & $\mathrm{x}$ & \\
7 & $\mathrm{x}$ & $\mathrm{x}$ & & $\mathrm{x}$ & $\mathrm{x}$ \\
\hline
\end{tabular}

- PV surplus (D.2): The PV surplus power is divided over the available EVs connected to the grid in order not to give preference to one or more vehicles. If the PV surplus per vehicle is less than the minimum charging power, the vehicles will charge with minimum charging power.

- Delayed (D.3): The EV charging (until fully charged batteries) is delayed as long as possible. The time step to start charging is calculated from the next departure time, the required energy and the available charging power.

Practically, it is assumed that the EV user can enter the next departure time (or when the charging should be completed). The available PV surplus for each EV can for instance be communicated by a building energy management system.

Different charging powers are examined, which are typical for mode 2 and mode 3 charging as defined in IEC 61851-1. Only single-phase $(230 \mathrm{~V})$ charging is considered here with the following charging powers available: $2.07 \mathrm{~kW}(10 \mathrm{~A}), 2.98 \mathrm{~kW}$ (16 A) and $5.96 \mathrm{~kW}(32 \mathrm{~A})$ [37]. A $10 \%$ margin takes into account the maximum allowed voltage deviations. An extra $10 \%$ margin is used to prevent tripping of standard 16/32 A fuses. This last margin is not used for the $10 \mathrm{~A}$ charging power (16 A fuse). To prevent a low partial load efficiency of the power electronics, it is assumed that the minimum charging power is $250 \mathrm{~W}$.

\section{RESULTS}

This section discusses the results for the case study, both the reference scenario without EVs and the different EV charging strategies regarding the grid impact, self-consumption of local PV generation and the UF. General conclusions are given in the discussion (Section V) and conclusion part (Section VI). Yearly simulations are performed to take into account the seasonal variations of the PV generation.

\section{A. Reference Scenario: no EVs}

Fig. 4 (a) shows the load duration diagram of the reference scenario without EVs. The demand and injection peak power are respectively $17 \mathrm{~kW}$ and $35.9 \mathrm{~kW}$. The demand and injection OPP are respectively $14.9 \mathrm{~kW}$ and $30 \mathrm{~kW}$. Since the PV system is undersized relative to the yearly power 


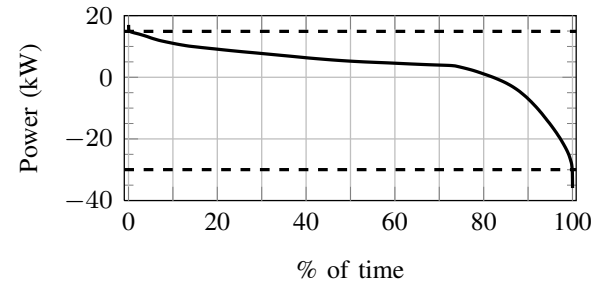

(a)

(b)

Fig. 4. Results reference scenario: (a) Load duration diagram and the OPPs (dashed line) and (b) the modified box plot to represent the load duration diagram. The inner box (black) spans the 25 th to 75 th percentiles. The outer box (white) spans the 5th to 95th percentiles. The outer whiskers extend to the minimum and maximum values. The OPPs (shorter line) are included.

consumption, due to the limited roof surface, and since the consumption of the different households is non-coincident, the self-consumption is $56.1 \%$. This means $43.9 \%$ of the surplus energy is injected into the distribution grid.

A modified box plot is used to represent the load profile throughout the rest of this paper. The box plot is illustrated in Fig. 4 (b). The inner box spans the 25th to 75th percentiles and the outer box spans the 5th to 95th percentiles. The outer whiskers extend to the peak values and the OPPs are included.

\section{B. Grid Impact of EVs}

Fig. 5 shows the modified box plots of the load duration diagrams for the different scenarios, EV penetration rates and charging powers. In the first scenario, night charging has no impact on the injection peaks. Due to a high simultaneity between the EV charging and evening household demand peak, an increased EV penetration rate and charging power rating result in higher demand power peaks and OPPs.

Individual peak shaving (scenario 2) during the night has a low impact on the peak powers for low charging powers. Nevertheless, the impact is high for a charging power of $5.96 \mathrm{~kW}$ and a high amount of EVs, e.g. a peak demand power decrease of almost $50 \%$ compared to scenario 1 for 20 vehicles. In all cases the demand OPP is much lower compared to the first scenario. Besides, the spreading of the EV charging in time is shown by the broader 25th to 75th percentile.

In scenario 3, the EVs are also charged when arriving at home during the day. This results in decreased night charging. As a result of this lower simultaneity with the household evening power demand, the OPP decreases compared to scenario 1. For a charging power rating of 2.07 and $2.98 \mathrm{~kW}$, the 25 th to 75 th percentile decreases compared to scenario 1 . However, this is not valid for the highest charging power rating. The decrease of the peak power is however very limited. The grid impact decreases even more when individual peak shaving is possible during the entire day (scenario 4). The demand peak power and OPP are even lower than in scenario 2 . Due to the daytime charging, also the injection peak power and OPP decrease, up to 5 and $10 \%$ for respectively scenario 3 and 4. This decrease is higher for individual peak shaving, since spreading the charging increases the simultaneity with $\mathrm{PV}$ power production.
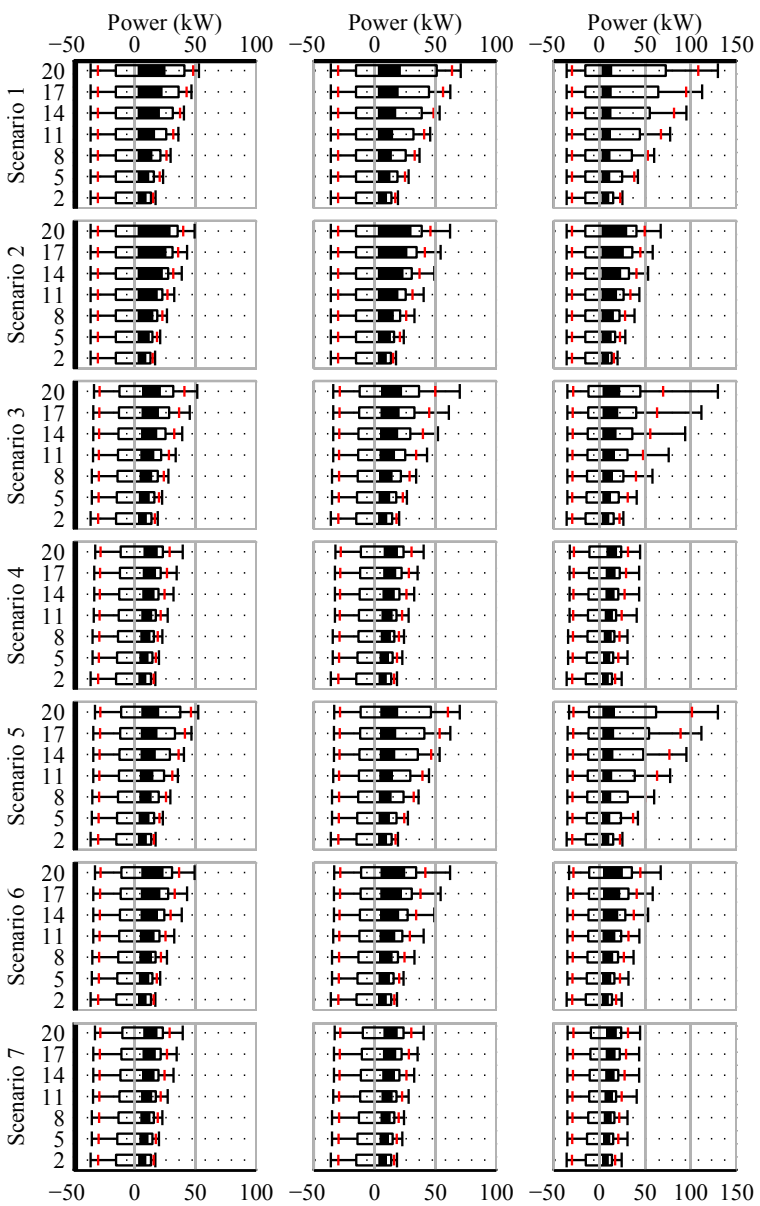

Fig. 5. Load duration diagrams (modified box plots) for the different charging scenarios and EV penetration rates (y-axis) for a charging power of $2.07 \mathrm{~kW}$ (left), $2.98 \mathrm{~kW}$ (middle) and $5.96 \mathrm{~kW}$ (right).

For scenario 5 and 6 , the charging during the day is delayed as long as possible making sure the mobility requirements are still met. Postponing the charging may result in a higher simultaneity of the EV charging with the household demand in the evening (before $10 \mathrm{pm}$ ). Therefore, the peak demand powers and the OPPs are a little higher compared to the uncoordinated charging in scenario 3 and 4 . On the other hand, the possibility to charge the surplus PV power, has a small positive impact on the injection peak power and OPP compared to scenario 3 and 4 . The impact of individual peak shaving (scenario 6 compared to scenario 5) is similar to the difference between the first and second scenario.

The last scenario can be compared to scenario 4 , but the individual peak shaving can be overruled if the PV power surplus is larger. This results in a higher PV self-consumption. The peak demand power and OPP are only slightly lower compared to scenario 4, which means that the peaks occur on days with low or no PV production.

As shown before, increasing the charging power rating leads to an increased grid impact regarding the demand power peaks and demand OPP. However, a higher charging power rating 
also has a negative impact on the injection power peaks and injection OPP. This has a twofold cause. First, a lower charging time leads to a simultaneity decrease with the PV power production. Second, in case of charging at times when the PV production is lower than the charging power, this local production is less optimally charged. This impact is larger for higher charging power ratings.

As a rule of thumb for apartment buildings without electrical heating, $2.5 \mathrm{kVA}$ per apartment is taken as connection capacity for the whole building. This results in a connection capacity of $50 \mathrm{kVA}$ for the apartment building. For the lowest charging power, there are virtually no cases with any overload assuming a power factor of one. In case of overload, this is for less than $1 \%$ of the time. For $2.98 \mathrm{~kW}$, overload occurs more frequently, however for less than $5 \%$ of the time. Only in scenario 4 and 7, the peak demand power is below $50 \mathrm{~kW}$ for an EV penetration rate of $100 \%$. Similar conclusions can be taken for the highest charging power. In case of an EV penetration rate of less than $14 \mathrm{EVs}$, there is no overload in any scenario.

\section{Impact on the Self-consumption}

The self-consumption of the building without EVs is $56.1 \%$. When only night charging occurs, this value remains unchanged. When daytime charging is possible, the selfconsumption increases, depending on the chosen charging strategy and charging power rating. This is shown in Table III.

In scenario 3 , uncoordinated charging during the day is applied, which results in a self-consumption increase of about $2.4 \%$ to $20.2 \%$ depending on the EV penetration rate. For a charging power of $2.98 \mathrm{~kW}$, the self-consumption drops compared to $2.07 \mathrm{~kW}$, due to faster charging and a lower simultaneity with PV power production. However, the selfconsumption decrease for $5.96 \mathrm{~kW}$ is less, which is explained by the fact that a higher amount of PV power can be used for charging. The self-consumption can be further increased when individual peak shaving is applied during both the day and night (scenario 4). The self-consumption increases because of two distinct reasons. First, due to individual peak shaving, the vehicles will be charged more during the day. On the other hand, spreading the charging during the day, the simultaneity between the charging and PV power production increases. When a higher charging power rating is available, the selfconsumption increase is larger.

When the charging during the day is delayed and the PV power surplus is charged (scenario 5), the self-consumption is higher than in the uncoordinated case (scenario 3). However, the minimum charging power results in a decreasing selfconsumption for an increase in charging power. The minimum charging power means that even when the PV power surplus per connected vehicle is lower than this value, the vehicle will charge at minimum charging power. Thus, the lower the charging power, the larger the simultaneity with the PV power production will be. Individual peak shaving during the night (scenario 6) will lead to more charging during the day, thus a higher self-consumption.

In the last scenario, individual peak shaving is applied during the night and day. During the day, the individual peak
TABLE III

SELF-CONSUMPTION (\%) FOR THE DIFFERENT CHARGING SCENARIOS (CS), EV PENETRATION RATES AND CHARGING POWER RATINGS (P).

\begin{tabular}{ccccccccc}
\hline \multirow{2}{*}{$\mathbf{C S}$} & $\mathbf{P}$ & \multicolumn{7}{c}{ Number of vehicles } \\
\cline { 2 - 9 } & {$[\mathbf{k W}]$} & 2 & 5 & 8 & 11 & 14 & 17 & 20 \\
\hline \multirow{3}{*}{3} & 2.07 & 57.5 & 59.8 & 61.8 & 63.5 & 64.9 & 66.1 & 67.5 \\
& 2.98 & 57.4 & 59.7 & 61.4 & 63.2 & 64.3 & 65.5 & 66.8 \\
& 5.96 & 57.5 & 60.6 & 62.2 & 64.0 & 65.0 & 66.3 & 67.5 \\
\hline \multirow{4}{*}{4} & 2.07 & 57.7 & 60.7 & 63.4 & 65.5 & 67.0 & 68.5 & 70.3 \\
& 2.98 & 57.7 & 60.9 & 63.5 & 65.7 & 67.2 & 68.7 & 70.6 \\
& 5.96 & 57.8 & 61.6 & 64.3 & 66.5 & 68.0 & 69.6 & 71.4 \\
\hline \multirow{3}{*}{5} & 2.07 & 57.8 & 60.8 & 63.3 & 65.4 & 67.0 & 68.5 & 70.2 \\
& 2.98 & 57.7 & 60.5 & 62.6 & 64.6 & 65.9 & 67.2 & 68.6 \\
& 5.96 & 57.8 & 61.0 & 62.7 & 64.6 & 65.6 & 66.7 & 67.8 \\
\hline \multirow{2}{*}{6} & 2.07 & 57.8 & 61.0 & 63.8 & 66.0 & 67.6 & 69.1 & 71.0 \\
& 2.98 & 57.8 & 60.9 & 63.2 & 65.3 & 66.7 & 68.0 & 69.6 \\
& 5.96 & 57.9 & 61.3 & 63.4 & 65.3 & 66.4 & 67.7 & 68.9 \\
\hline \multirow{2}{*}{7} & 2.07 & 57.9 & 61.4 & 64.6 & 67.1 & 68.8 & 70.5 & 72.5 \\
& 2.98 & 58.1 & 61.8 & 65.0 & 67.5 & 69.3 & 71.0 & 73.1 \\
& 5.96 & 58.3 & 62.8 & 63.4 & 68.5 & 70.2 & 72.0 & 74.0 \\
\hline
\end{tabular}

shaving can be overruled to charge during PV power surplus. This charging strategy results in the highest self-consumption. A charging power rating of $2.07 \mathrm{~kW}$ even leads to a higher self-consumption than in the other scenarios.

\section{Impact on the Utility Factor of EVs}

Table IV shows the average UF of the fleet for the different scenarios and charging power rates. The scenarios can be divided in three groups of scenarios: (i) scenarios with only night charging (Scenario 1 and 2), (ii) scenarios with night and day charging without individual peak shaving during the day (Scenario 3, 5 and 6) and (iii) scenarios with individual peak shaving during the day (Scenario 4 and 7).

Increasing the charging power results in a higher UF, since the batteries can be charged more in case the battery was not fully charged in case of a lower charging power. With further increases in charging power, its additional impact decreases.

For identical charging powers, adding daytime charging results in a higher UF. In that case, the impact of a higher charging power decreases even more.

When daytime individual peak shaving is applied, the UFs increase. This is due to the fact that in the chosen charging algorithm, the charging power is recalculated at each time step in order to have a fully charged battery at departure.

TABLE IV

THE AVERAGE UTILITY FACTOR OF THE 20-VEHICLE FLEET FOR THE DIFFERENT CHARGING STRATEGIES AND CHARGING POWER RATINGS.

\begin{tabular}{rlrc}
\hline & \multicolumn{3}{c}{ Charging power rating } \\
\cline { 2 - 4 } Charging strategy & $2.07 \mathrm{~kW}$ & $2.98 \mathrm{~kW}$ & $5.96 \mathrm{~kW}$ \\
\hline Night & $88.6 \%$ & $92.2 \%$ & $93.3 \%$ \\
Night \& day & $93.2 \%$ & $93.9 \%$ & $94.4 \%$ \\
Daytime individual peak shaving & $94.5 \%$ & $95.0 \%$ & $95.2 \%$ \\
\hline
\end{tabular}




\section{E. Higher Residential Charging Power Ratings}

There is a trend towards higher charging power ratings for EVs since it may help to overcome range-anxiety, it might be required to meet the driving behavior requirements and it increases the charging flexibility. Nevertheless, for residential EV charging, the extra investments in charging infrastructure will have to be weighed against the benefits and drawbacks shown in this section. So far, the EV charging power ratings are limited to $5.96 \mathrm{~kW}$ in this discussion. With a three-phase connection, the ratings can be increased to $8.94 \mathrm{~kW}$ and $17.88 \mathrm{~kW}$ for respectively a $16 \mathrm{~A}$ and $32 \mathrm{~A}$ connection if standard 16/32 A fuses are used.

For a charging power rating of $5.96 \mathrm{~kW}$, Table $\mathrm{V}$ gives the number of charging opportunities for which a charging power is required that is higher than 5.96, 8.94 and $17.88 \mathrm{~kW}$ to fully charge the battery by the next departure time. A charging opportunity is considered as each period after arrival at home. When only night charging is available (first and second scenario), only about $1.3 \%$ of the nightly charging opportunities require a charging power that is higher than $5.96 \mathrm{~kW}$. When night charging is complemented by day charging, this increases to 6.6 to $7.8 \%$, depending on the charging scenario. These numbers are higher since there are more charging opportunities and the time at home between two trips is generally shorter during daytime.

TABLE V

THE NUMBER OF CHARGING OPPORTUNITIES (\%) AT HOME THAT THE REQUIRED CHARGING POWER, TO FULLY CHARGE THE EVS BY THE NEXT DEPARTURE MOMENT, IS HIGHER THAN A CERTAIN POWER.

\begin{tabular}{rccc}
\hline Charging period & $>5.96 \mathrm{~kW}$ & $>8.94 \mathrm{~kW}$ & $>17.88 \mathrm{~kW}$ \\
\hline Night & $1.3 \%$ & $1.1 \%$ & $0.5 \%$ \\
Night \& day & $6.6-7.8 \%$ & $4.1-5.1 \%$ & $1.6-1.9 \%$ \\
\hline
\end{tabular}

Nevertheless, it should be noted that Table V represents the worst-case numbers, since charging at a higher power during a charging opportunity may reduce the required charging power during future charging opportunities. Also, it does not take into account if the driving behavior requires a fully charged battery, i.e. a higher charging power, at each departure at home and the numbers do not include any charging opportunities at other places. Also note that these numbers do not contain information on the length of each charging opportunity.

The results on the UF in Section IV-D showed a decreasing impact on the UF for higher charging power ratings due to a lower increase of the power consumption. For a charging power rating of $8.94 \mathrm{~kW}$, the increase in power consumption is even smaller compared to the difference between $2.98 \mathrm{~kW}$ and $5.96 \mathrm{~kW}$. Therefore, the UF only slightly increases compared to the UF for a charging power rating of $5.96 \mathrm{~kW}$; up to 0.13 percentage points, depending on the charging scenario.

\section{DISCUSSION}

As a result of long standstill times and the high grid connection probability during daytime for EVs, additional daytime charging can result in benefits for different actors.
For the EV user, additional charging in general increases his electric driving range. Second, daytime charging decreases the simultaneity of EV charging with the residential power peak, which occurs in general at the beginning of the nighttariff period. Furthermore, it increases the simultaneity with the local PV production. Therefore, the DSO benefits from a lower grid impact. The TSO may benefit from an improved renewable integration. On the other hand, the spreading of EV charging may increase the simultaneity of the EV charging with the high demand at TSO level during daytime.

In general, individual peak shaving decreases the charging powers as a result of the long standstill times of the EVs. Therefore, peak power demand of EV charging is significantly reduced. Moreover, due to the spreading of the EV charging in time, the simultaneity of the EV charging and the local PV generation increases, resulting in a higher self-consumption. The EV owner in turn benefits from an increased battery lifetime due to lower charging currents [35].

Increasing the residential charging power increases the grid impact, but it also increases the charging flexibility and it allows to charge higher PV production peaks. Since vehicles have on average long standstill times at home, the results show that the need for three-phase charging at home is very low. Therefore, increasing the charging power has a decreasing positive impact on the electric range and self-consumption.

\section{CONCLUSIONS}

The charging of multiple PHEVs in an apartment building, equipped with a PV system, is discussed. Different charging strategies are investigated which take advantage of the available EV charging flexibility. These strategies require only limited prior knowledge to coordinate the charging without the need for optimization and they require minimal communication infrastructure. With these simple strategies, the grid impact of a residential building, which incorporates EV charging, can be significantly reduced.

The simplest solution to decrease the local grid impact and to increase the electric EV range, is to encourage daytime EV charging at all possible locations. This incorporates the principle of charging when the car is parked instead of stopping for charging, which is valid for conventional vehicles [37]. Although the latter may be inevitable due to a limited electric range. Nevertheless, a suitable charging strategy is required at these other locations to charge the EVs in a grid-friendly manner, both from a DSO and TSO point-of-view.

Individual peak shaving can be seen as an important strategy to be implemented on EVs in the near future, in order to limit the grid impact of EV charging without influencing the mobility behavior. Individual peak shaving can be implemented on the EV onboard battery management system and does not need any communication infrastructure and only requires the next departure time and present battery SOC as input. However, an incentive is needed for the EV owner to adopt this strategy.

Less than $10 \%$ of the residential charging opportunities require three-phase charging. Therefore, higher power ratings at residential buildings have a negligible impact on the electric driving range. These higher power ratings require extra investments in e.g. charging infrastructure and have an increasing 
grid impact. On the other hand, higher charging powers can be combined with individual peak shaving. The latter allows to decrease the grid impact, to overcome range-anxiety and to increase the charging flexibility.

\section{REFERENCES}

[1] "Energy Technology Perspectives 2012: Pathways to a Clean Energy System," International Energy Agency, Tech. Rep., 2012.

[2] The European Commission. (2013, Apr.) The EU Climate and Energy Package. [Online]. Available: http://ec.europa.eu/clima/policies/package/

[3] "Directive 2010/31/EU of the European Parliament and the Council on 19 May 2010 on the Energy Performance of Buildings (recast)," The European Parliament, Tech. Rep., 2010.

[4] A. Marszal, P. Heiselberg, J. Bourrell, E. Musali, K. Voss, I. Sartori, and A. Napolitano, "Zero Energy Building - A Review of Definitions and Calculation Methodologies," Energy and Buildings, vol. 43, no. 4, pp. 971-979, Apr. 2011.

[5] G. Heydt, "The Impact of Electric Vehicle Deployment on Load Management Strategies," IEEE Power Eng. Rev., vol. 3, no. 5, pp. 41-42, May 1983.

[6] G. Papaefthymiou, B. Hasche, and C. Nabe, "Potential of Heat Pumps for Demand Side Management and Wind Power Integration in the German Electricity Market," IEEE Trans. Sustain. Energy, vol. 3, no. 4, pp. 636-642, Oct. 2012.

[7] M. Duvall, E. Knipping, M. Alexander, L. Tonachel, and C. Clarc, "Environmental Assessment of Plug-In Hybrid Electric Vehicles," Electric Power Research Institute, Tech. Rep. 1015325, 2007.

[8] (2013, Apr.) Flemish Regulator for the Energy and Gas markets (VREG). [Online]. Available: http://www.vreg.be

[9] J. Van Roy, N. Leemput, S. De Breucker, F. Geth, P. Tant, and J. Driesen, "An Availability Analysis and Energy Consumption Model for a Flemish Fleet of Electric Vehicles," in European Electric Vehicle Congr., Brussels, Belgium, Oct. 2011.

[10] R. Passey, T. Spooner, I. MacGill, M. Watt, and K. Syngellakis, "The Potential Impacts of Grid-Connected Distributed Generation and How to Address Them: A Review of Technical and Non-Technical Factors," Energy Policy, vol. 39, no. 10, pp. 6280-6290, Oct. 2011.

[11] N. Leemput, F. Geth, B. Claessens, J. Van Roy, R. Ponnette, and J. Driesen, "A Case Study of Coordinated Electric Vehicle Charging for Peak Shaving on a Low Voltage Grid," in IEEE PES Innovative Smart Grid Technologies (ISGT) Europe, Berlin, Germany, October 1417, 2012.

[12] R. Baetens, R. De Coninck, J. Van Roy, B. Verbruggen, J. Driesen, L. Helsen, and D. Saelens, "Assessing Electrical Bottlenecks at Feeder Level for Residential Net Zero-Energy Buildings by Integrated System Simulation," Appl. Energy, vol. 96, pp. 74-83, Aug. 2012.

[13] K. Clement, E. Haesen, and J. Driesen, "The Impact of Vehicle-to-Grid on the Distribution Grid," Electric Power Syst. Research J., vol. 81, no. 1, pp. 185-192, Jan. 2011.

[14] N. Leemput, J. Van Roy, F. Geth, P. Tant, and J. Driesen, "Comparative Analysis of Coordination Strategies for Electric Vehicles," in IEEE PES Innovative Smart Grid Technologies (ISGT) Europe, Manchester, United Kingdom, Dec. 2011

[15] T. Nuytten, B. Claessens, K. Paredis, J. Van Bael, and D. Six, "Flexibility of a Combined Heat and Power System With Thermal Energy Storage for District Heating," Appl. Energy, vol. 104, pp. 583-591, Apr. 2013.

[16] F. Geth, N. Leemput, J. Van Roy, J. Büscher, R. Ponnette, and J. Driesen, "Voltage Droop Charging of Electric Vehicles in a Residential Distribution Feeder," in IEEE PES Innovative Smart Grid Technologies (ISGT) Europe, Berlin, Germany, October 14-17, 2012.

[17] A. Bedir, B. Ozpineci, and J. E. Christian, "The Impact of Plug-In Hybrid Electric Vehicle Interaction with Energy Storage and Solar Panels on the Grid for a Zero Energy House," in IEEE PES Transmission and Distribution Conf. and Expo., New Orleans, USA, Apr. 2010.

[18] K. Mets, T. Verschueren, W. Haerick, C. Develder, and F. De Turck, "Optimizing Smart Energy Control Strategies for Plug-In Hybrid Electric Vehicle Charging," in IEEE/IFIP Network Operations and Manage. Symp. Workshops, Osaka, Japan, Apr. 2010.

[19] L. Jian, H. Xue, G. Xu, X. Zhu, D. Zhao, and Z. Shao, "Regulated Charging of Plug-in Hybrid Electric Vehicles for Minimizing Load Variance in Household Smart Micro-Grid," IEEE Trans. Ind. Electron., vol. PP, no. 99 , p. 9 pages, Early access article.
[20] H. K. Nguyen and J. B. Song, "Optimal Charging and Discharging for Multiple PHEVs with Demand Side Management in Vehicle-toBuilding," J. of Commun. and Netw., vol. 14, no. 6, pp. 662-671, Dec. 2012 .

[21] I. Momber, T. Gomez, G. Venkataramanan, M. Stadler, S. Beer, J. Lai, C. Marnay, and V. Battaglia, "Plug-In Electric Vehicle Interactions With a Small Office Building: An Economic Analysis Using DER-CAM," in IEEE PES General Meeting, Minneapolis, USA, Jul. 2010.

[22] S. Derakhshandeh, A. Masoum, S. Deilami, M. Masoum, and M. Hamedani Golshan, "Coordination of Generation Scheduling with PEVs Charging in Industrial Microgrids," IEEE Trans. Power Syst., vol. PP, no. 99, pp. 1-11, 2013.

[23] M. Bozchalui and R. Sharma, "Analysis of Electric Vehicles as Mobile Energy Storage in Commercial Buildings: Economic and Environmental Impacts," in IEEE PES General Meeting, San Diego, USA, Jul. 2012.

[24] L. Jerram and J. Gartner, "Electric Vehicle Charging Equipment," Navigant Research, London, United Kingdom, Tech. Rep., 2012.

[25] T. Lyon, M. Michelin, A. Jongejan, and T. Leahy, "Is "Smart Charging" Policy for Electric Vehicles Worthwhile?" Energy Policy, vol. 41, pp. 259-268, Feb 2012

[26] J. Salom, J. Widén, J. Candanedo, I. Sartori, K. Voss, and A. Marszal, "Understanding Net Zero Energy Buildings: Evaluation of Load Matching and Grid Interaction Indicators," in Building Simulations, Sydney, Australia, Sep. 2011

[27] B. Verbruggen, R. De Coninck, R. Baetens, D. Saelens, L. Helsen, and J. Driesen, "Grid Impact Indicators for Active Building Simulation," in IEEE PES Innovative Smart Grid Technologies (ISGT), California, USA, Jan. 2011.

[28] R. De Coninck and G. Verbeeck, "Technisch-Economische Analyse van de Rendabiliteit van Energiebesparende Investeringen," Brussels Instituut voor Milieubeheer, Tech. Rep. Energie/E04-154, Aug. 2005.

[29] J. Ordòñez, E. Jadraque, J. Alegre, and G. Martínez, "Analysis of the Photovoltaic Solar Energy Capacity of Residential Rooftops in Andalusia (Spain)," Renewable and Sustainable Energy Reviews, vol. 14 no. 7, pp. 2122-2130, Sep. 2010.

[30] W. De Soto, S. Klein, and W. Beckman, "Improvement and Validation of a Model for Photovoltaic Array Performance," Solar Energy, vol. 80, no. 1 , pp. 78-88, 2006.

[31] B. Verbruggen, J. Van Roy, R. De Coninck, R. Baetens, L. Helsen, and J. Driesen, "Object-Oriented Electrical Grid and Photovoltaic System Modelling in Modelica," in 8th Int. Modelica Conf., Dresden, Germany, Mar. 2011.

[32] Meteotest 2008, "Meteonorm version 6.1 - edition 2009."

[33] (2013, Apr.) Sanyo. [Online]. Available: http://www.sanyo.be

[34] J. Tant, F. Geth, D. Six, P. Tant, and J. Driesen, "Multi-Objective Battery Storage to Improve PV Integration in Residential Distribution Grids," IEEE Trans. Sustain. Energy, vol. 4, no. 1, pp. 182-191, 2013.

[35] J. Dogger, B. Roossien, and F. Nieuwenhout, "Characterization of LiIon Batteries for Intelligent Management of Distributed Grid-Connected Storage," IEEE Trans. Energy Convers., vol. 26, no. 1, pp. 256-263, Mar. 2011.

[36] "Fuel Economy Labeling of Motor Vehicles: Revisions to Improve Calculation of Fuel Economy Estimates," U.S. Environmental Protection Agency, Tech. Rep. EPA420-R-06-017, Dec. 2006.

[37] C. Ricaud and P. Vollet, "Connection System on the Recharging Spot: A Key Element For Electric Vehicles," White Paper, Schneider Electric. [Online]. Available: http://www.schneiderelectric.com/sites/corporate/en/support/white-papers/recharging-spotelectric-vehicles.page

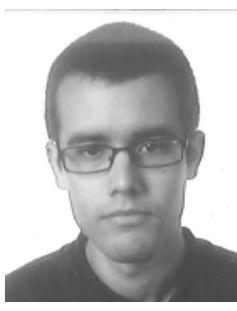

Juan Van Roy (S'09) received the M.Sc. degree in Electrical Engineering with specialization in energy, from the KU Leuven, Belgium, in 2010. Currently, he is working as a research assistant with the division ESAT-Electa towards the Ph.D. degree at the KU Leuven. He is funded through a doctoral scholarship of the Flemish Institute for Technological Research (VITO) and the PhD School of KIC InnoEnergy.

His research interests include integrating and controlling the electric vehicle charging and their interaction with thermal energy flows in buildings. 
This is the author's version of an article that has been published in this journal. Changes were made to this version by the publisher prior to publication. The final version of record is available at http://dx.doi.org/10.1109/TSTE.2013.2281463

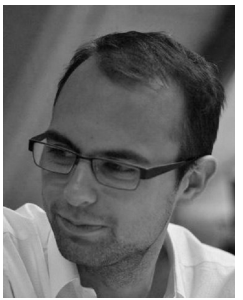

Niels Leemput (S'11) received the M.Sc. degree in Electrical Engineering, with specialization in energy, from the KU Leuven, Belgium, in 2010. Currently, he is working as a research assistant with the division ESAT-Electa towards the Ph.D. degree at the KU Leuven. He is funded by IWT-Vlaanderen.

His research interests include the grid integration of charging infrastructure for electric vehicles and power electronics for grid-coupling of electrical vehicles.

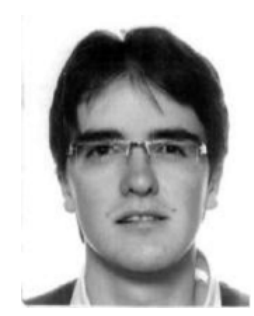

Frederik Geth (S'10) received the M.Sc. degree in Electrical Engineering from the KU Leuven, Belgium, in 2009. Currently, he is working as a research assistant with the division ESAT-Electa.

His research interests include optimal storage integration in distribution grids, batteries for (hybrid) electrical vehicles and controlling the impact of the charging currents of (hybrid) electrical vehicles on the grid.

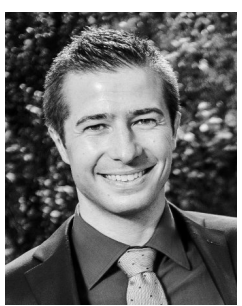

Robbe Salenbien received his M.Sc and Ph.D. degree in Physics at the KU Leuven in 2007 and 2012 respectively. Currently, he is working as a researcher in energy technology at the Flemish Institute for Technological Research (VITO).

His interests include renewable energy technologies, thermal networks, smart energy districts and intelligent energy management.

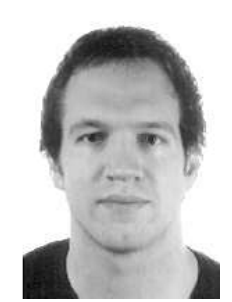

Jeroen Büscher (M'11) received his M.Sc and $\mathrm{Ph} . \mathrm{D}$. degree in Physics at the University of Ghent in 2005 and at the KU Leuven in 2010, respectively. In 2011 he joined the ESAT-Electa division of the KU Leuven as a postdoctoral researcher.

His interests include the smart grid integration of charging infrastructure for electric vehicles and the modeling of electrical energy systems.

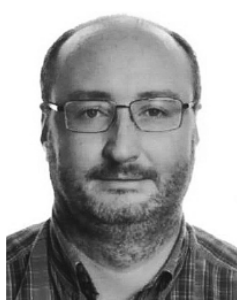

Johan Driesen (S'93 - M'97 - SM'12) received the M.Sc. and Ph.D. degrees in Electrical Engineering from the KU Leuven, Leuven, Belgium, in 1996 and 2000, respectively. Currently, he is a Professor with the KU Leuven and teaches power electronics and electric drives.

In 2000, he was with the Imperial College of Science, Technology and Medicine, London, U.K. In 2002, he was with the University of California, Berkeley.

Currently, he conducts research on distributed generation, power electronics, and its applications. 